\title{
Research on the Blended Teaching Mode of Advanced Mathematics Based on "MOOC"
}

\author{
Zhang Xuefu \\ He Xi University, Zhangye, Gansu, 734000, China
}

Keywords: MOOC; advanced mathematics; blended teaching

\begin{abstract}
With the rapid development of the society, education is gradually changing, and a new type of teaching model has been formed in the teaching. This kind of teaching mode is based on the information network technology platform. In this research, the author studied the blended teaching mode of advanced mathematics based on "MOOC", analyzed the characteristics of the blended teaching of advanced mathematics at present stage, discussed the importance of this teaching mode in the application process, and explored how to better apply the MOOC blended teaching mode into the teaching of advanced mathematics. It is expected that this study can provide a reference for advanced mathematics teaching in colleges and universities in China.
\end{abstract}

\section{Introduction}

In the process of social development in recent years, the continuous innovation and development of Internet information technology has promoted the transformation of teaching mode in China to a certain extent. Nowadays, the most common and multi-purpose Internet course management teaching system and learning management system have promoted the development of information technology teaching in our country. More and more colleges and universities have gradually begun to attach importance to the teaching of electronic information technology in schools [1]. The functions of many teaching software are more and more powerful. And the teaching software "Moodle" has been widely used in courses in colleges and universities. MOOC teaching mode is a kind of large open network platform course teaching which we proposed in the course of teaching [2]. This kind of teaching mode is gradually rising in recent years, breaking the traditional teaching mode of our country and putting forward a new challenge to our traditional teaching mode. Therefore, this study explores the blended teaching model of Advanced Mathematics in MOOC.

\section{Development status of blended teaching mode based on MOOC}

From the current situation of the application of blended teaching mode in colleges and universities, many large web browser learning conditions have basically been met, but there are still many drawback on learning technology conditions of mobile terminals. The current stage of college teaching mode in our country is inevitable in the era of information internet development [3]. People's network contact time is obviously more, then in the course of carrying out the teaching of advanced mathematics, it is very important to achieve the terminal operation. If they simply learn the basic theoretical knowledge, it will inevitably make students be not interested in the learning of advanced mathematics courses, and the advanced mathematics textbooks teaching resources are often too limited. Therefore, MOOC is required to be applied to the teaching of higher education at this stage. In addition, in advanced mathematics teaching, realizing the MOOC learning of advanced mathematics through computer terminal equipment effectively solves the problem that students using computer equipment to solve the problems in more details in the process of learning advanced mathematics. In the process of advanced mathematics learning, there will inevitably be many contradictions, such as the difference of learning level, the teaching content is too broad to be started, the degree of mastery is too limited [4]. The MOOC blended teaching model can better solve the above problems, so as to promote the overall advanced mathematics learning effect. 


\section{The importance of applying the MOOC course teaching in advanced mathematics teaching}

With the continuous change in the social development of our country, the teaching mode has gradually changed. In the process of teaching, the major colleges and universities in our country have gradually shifted their emphasis from elite teaching to popular education the grassroots level [5]. Advanced mathematics is different from other disciplines in the learning process. The traditional mode teaching is usually used in the course teaching. Such a monotonous, monoagent teaching model usually fails to arouse students' interest in learning advanced mathematics. Students in the classroom learning process are often too passive to be proactive learning. Thus, in the teaching of advanced mathematics, how to guide students to actively participate in learning has become an important issue at this stage. From another level, we can find that in the teaching of advanced mathematics, many course textbooks are still too traditional and do not conform to the current advanced mathematics teaching needs. In the current rapid development of computer information technology society, the Internet platforms provide a broader space for advanced mathematics learning. In order to further enhance students 'overall interest in learning, MOOC can be used to maximize the students' motivation of advanced mathematics learning by applying it in advanced mathematics teaching process.

\section{Constructing blended advanced mathematics teaching mode based on MOOC}

\subsection{Operation mode of advanced mathematics teaching based on MOOC}

In the teaching process of advanced mathematics courses, by applying MOOC courses into advanced mathematics course teaching, teachers can release the advanced mathematics knowledge that they are going to teach and highlight the problems to be solved in advanced mathematics course by the Internet platforms. Students usually make use of the many small softwares on the network platform to better realize autonomous learning [6]. Furthermore, teachers can make use of the Internet information platform to enable students to form their own learning experiences during the course of advanced mathematics classes and communicate with other students on the Internet platform. In this new teaching mode, we can find out clearly that the advanced mathematics teachers in colleges and universities will inevitably make the corresponding teaching changes. Teachers are no longer the mainstay of the traditional teaching mode, but the leader and discoverer, and also the coordinator and organizer. By using this learning platform, students have better realized autonomous learning. It realizes the mutual communication between teachers and students, and provides more learning opportunities and learning environment.

\subsection{Building a MOOC blended teaching mode of advanced mathematics}

In order to further promote the overall teaching quality of the advanced mathematics teaching courses in colleges and universities, the teaching mode of the advanced mathematics courses mainly covers four different teaching stages [7]. In other words, in the process of arranging the teaching content of the curriculum, the students first learn about the targeted learning contents before the class. In the course of classroom teaching, teachers and students do the pertinent discussion on these topics.

In the first stage, teachers need to design the main teaching content and corresponding teaching mode before the course is started. And in this process, the differences of students' learning degree should be taken into consideration, and specific teaching objectives and difficult teaching focus should be made clear. Furthermore, teachers need to make appropriate adjustments to the teaching structure of the course during the production of the MOOC course so that the MOOC can contain more points of knowledge and ensure the overall interest of the whole course.In the teaching process, teachers should add more varied exercises and thinking in accordance with the content of advanced mathematics, so as to achieve the common combination of handwritten boards and multimedia.

In the second stage, students need to clear their own specific circumstances of advanced mathematics learning, to complete the targeted preview and practice of advanced mathematics. 
They should be able to create their own relevant questions into pictures or small videos and upload them to the MOOC course learning platform to provide reference for teachers and other students in teaching and learning and open up a discussion of the problems.

In the third stage, that is, the classroom teaching of the advanced mathematics courses, teachers can explain the points according to the main knowledge about video in MOOC teaching so that students can better integrate the relevant knowledge points existing in the blackboard during the course learning. Students are better able to focus their attention and meet the student's own interest in learning.

In the fourth stage, after the teaching of the advanced mathematics course is carried out, teachers and students can make use of the MOOC teaching platform on the Internet to solve the problems arising from the course development so as to reach the mutual exchange and confusion between teachers and students. The process of communication and interaction is a particularly crucial learning method for students to accumulate knowledge they learned at the present stage, to achieve self-improvement, and to achieve self-perfection. Students can accumulate the teacher's teaching points of knowledge and teaching materials in the advanced mathematics classroom teaching process. To achieve the exchange of communication between students, so as to accumulate advanced mathematics knowledge they have learned and effectively improve the students' ability to learn advanced mathematics, so that students no longer be afraid of advanced mathematics learning.

\section{The significance of the change of the advanced mathematics and MOOC blended teaching mode in colleges and universities}

Applying the above MOOC blended teaching mode into the teaching of advanced mathematics teaching in colleges and universities can change the traditional teaching mode which is boring and monotonous. And that will enhance the students' learning initiative. Because of its overall teaching mode and the characteristics of advanced mathematics itself, the traditional advanced mathematics teaching provides a great shortage for the advanced mathematics courses [8]. So by applying MOOC blended teaching mode to the teaching of advanced mathematics in colleges and universities, the main value of the teaching application lies in the following aspects: One is the introduction of MOOC course teaching in the teaching of advanced mathematics can effectively improve the overall teaching quality and teaching effectiveness of the advanced mathematics courses. Teachers can also effectively change the teaching mode in classroom teaching, save the time spent in traditional teaching, and promote the students' self-regulated learning habits within a limited learning time. The second is when carry out the advanced mathematics MOOC courses in colleges and universities, students no longer subject to the classroom, teaching materials and many other limitations in the learning process. While, In the Internet MOOC curriculum platform, students expand their knowledge of learning so that they can better find problems, solve problems, analyze problems and summarize problems during the process of learning advanced mathematics. The third is that MOOC course teaching can set up different curriculum syllabus based on the teaching needs of different courses, and truly improve the overall teaching efficiency.

\section{Conclusions}

All in all, through carrying out MOOC course teaching in advanced mathematics in colleges and universities has changed the traditional teaching methods. It can better teaching students according to their aptitude and effectively change their own learning styles according to the specific implementation of the curriculum, improve students' comprehensive analytical skills, and improve students' learning initiative in learning advanced mathematics. And it also changed the status of teachers and students in the traditional classroom teaching in advanced mathematics and achieves the advanced mathematics teaching with students as the subject. Such a new teaching mode will surely be able to effectively promote the advanced mathematics teaching reform in Chinese colleges and universities. 


\section{References}

[1] Liu Lijun. Exploration on the Reform of Blended Teaching Mode Based on MOOC -- Taking Advanced Mathematics Course as an Example[J]. Education Forum, 2017(37):104-105.

[2] Li N, University D O. Discussion on the application of mixed teaching mode of MOOC course based on Information Technology[J]. Journal of Jiamusi Vocational Institute, 2017.

[3] Zhang Lin, Yue Guoqing. Research on Blended Teaching Model of Applied Undergraduate Based on MOOC Platform[J]. Journal of Heihe University, 2017(3):64-65.

[4] Luo Guiqiong. Research on the Application of MOOC based Blended teaching mode -- Taking Computer CourseES as Example[J]. Asia-Pacific Education, 2016(33):118-118.

[5] Li Feng, Guo Xiaofang, Zhang Zhenkai. Research and Practice of Blended Teaching Mode of Postgraduate Courses Based on MOOC[J]. Meitan Higher Education, 2017(3):64-67.

[6] Zhang Yu, Zhao Liang, Zhang Hongyan. Research on Blended Teaching Mode based on MOOC --A Case Study of C Language Programming Course[J]. Computer Knowledge and Technology, 2017, 13(4):125-126.

[7] Xiong Z T. The design and implementation of software engineering curriculum blended teaching mode based on MOOC[J]. Journal of Science of Teachers College \& University, 2016.

[8] Yang Fan, Wu Heli, Luo Chenhui. Research on the Design of Blended Teaching Mode based on MOOC -- A Case Study of "Automobile Insurance and Claims" Course[J]. Hunan Agricultural Machinery, 2017, 44(5):198-198. 